\title{
A Pre-Post Study on Efficacy of Celecoxib and Ibuprofen for Acute Low Back Pain among Orthopaedic Patients at Security Forces Hospital, Makkah, Saudi Arabia
}

\author{
Khalid H. Alzahrani ${ }^{1}$, Ethar A. Imam², Mohamed Izham Mohamed Ibrahim ${ }^{3 *}$ \\ ${ }^{1}$ Orthopaedic Surgery Department, Security Forces Hospital, Makkah, SAUDI ARABIA. \\ ${ }^{2}$ Pharmaceutical Care Department, Security Forces Hospital, Makkah, SAUDI ARABIA. \\ ${ }^{3}$ Clinical Pharmacy and Practice Section, College of Pharmacy, Qatar University, Doha, QATAR.
}

Received: 3 March 2017;
Accepted: 25 April 2017
*Correspondence to:

Professor Mohamed Izham Mohamed Ibrahim,

PhD,

Clinical Pharmacy and Practice Section, College of Pharmacy, Qatar University, Doha, Qatar. Email:mohamedizham@qu.edu.qa

Copyright: (C) the author(s),publisher and licensee Indian Academy of Pharmacists. This is an openaccess article distributed under the terms of the Creative Commons Attribution Non-Commercial License, which permits unrestricted non-commercial use, distribution, and reproduction in any medium, provided the original work is properly cited.

\begin{abstract}
Background: The safety and efficacy of Celecoxib and Ibuprofen have not been adequately examined among orthopaedic Arab patients. This prospective study was carried out to compare the benefits of Celecoxib and Ibuprofen with reference to factors affecting patients with acute low back pain. Methods: Pre-post study was carried out at orthopaedic Out Patient Department at Security Forces Hospital, Makkah, and KSA. One hundred and nine patients were randomly selected and assigned randomly to two treatment groups: Celecoxib 400 mg, and lbuprofen $100 \mathrm{mg}$. Pain was assessed using the World Health Organization pain scale. The decrease in pain score was calculated using a standardized system and was recorded on Day 5 and Day 10 of the patients follow up visits. Paired sample t-test, Mann-Whitney test and Chi-Square test were used at alpha level 0.05. Results: All the patients were Saudi nationals. Patients' age for Celecoxib group ranged from 20 - 59 years $(34.2+10.9)$, while for lbuprofen group ranged between $22-57$ years $(31.3+7.3)$. There were significant reductions in pain by both Celecoxib and Ibuprofen at the second follow-up visit, for all patients during walking, twisting, and while sitting in chair $(p<0.05)$. Celecoxib $(400 \mathrm{mg}$ ) was superior to lbuprofen $(100 \mathrm{mg})$ in reducing acute low back pain of the study population $(p<0.05)$. The pain scores of patients receiving celecoxib and ibuprofen were significantly improved from Day 5 to Day 10. Conclusion: Celecoxib was more effective than lbuprofen in reducing acute low back pain among the study population.
\end{abstract}

Key words: Acute Low Back Pain, Evaluation, Management, Non-Steroidal Anti-Inflammatory Drugs, Orthopaedic Patients, Outpatient, Pain Scale.

\section{INTRODUCTION}

Acute low back pain (ALBP) may be defined as an episode which persists for less than 6 weeks, and is associated with actual or potential tissue damage. ${ }^{[1]}$ ALBP is among the most common reasons for patients to seek medical care, and is usually localized between the shoulder blades and the folds of the buttocks. ${ }^{[2,3]}$ Over $40 \%$ of hospitalized patients and those presenting to the emergency department were reported to be suffering from ALBP. ${ }^{[4]} \mathrm{Up}$ to $80 \%$ of the world population were found to have complained from acute/chronic low back pain during some point in their life. ${ }^{[5]}$ The management of ALBP depends on the cause of pain, and can be medical, surgical, or both. Medical treatment usually includes drug therapy, rest, and exercise. Surgical treatment is 
indicated when medical treatment fails. Non-steroidal antiinflammatory drugs (NSAIDs) eg Celecoxib, Ibuprofen, as well as muscle relaxants are the commonly used drugs for treatment of ALBP. In a multidisciplinary expert panel study from the Middle East region, ${ }^{[4]}$ on drug treatment of acute low back pain, NSAIDs were recommended for treatment of ALBP. The American Pain Society conducted an important study on the recommended drugs for low back pain, NSAIDs, including Ibuprofen, were ranked first as short term effective drugs against ALBP. ${ }^{[2]}$ In a recent study at a tertiary care hospital in Nepal, NSAIDs were reported to be effective and safe for treatment of ALBP..$^{[4]}$ In the Kingdom of Saudi Arabia (KSA), the prevalence of low back pain was reported to be $18.8 \%$ among the general population in a study from Qassim region. ${ }^{[6]}$ However, in a categorized surgical room staff of a tertiary care hospital in Makkah, the prevalence of low back pain was found to be $74.2 \%{ }^{\left[{ }^{[7]}\right.}$ Most of the published research from KSA was on evaluating the effects of NSAIDs among categorized patient groups such as nurses, school workers, dental professions, and surgical room staff. ${ }^{[8-11]}$ Celecoxib was the first NSAID designed to alleviate acute pain by inhibiting the activity of the enzyme COX 2 responsible for pathogenesis of pain. Ibuprofen is the NSAID which is commonly used instead of Celecoxib for emergency treatment of ALBP among orthopaedic patients. To the best of our knowledge, and literature search, the safety and efficacy of Celecoxib and Ibuprofen have not been adequately examined among orthopaedic Saudi patients.

The purpose of the present prospective study was to compare the benefits of Celecoxib and Ibuprofen with reference to factors affecting acute low back pain among patients seen at Security Forces Hospital -Makkah (SFH-M) KSA. We also aim to determine the association of patient age, gender, with the safety and efficacy of Celecoxib and Ibuprofen.

\section{MATERIAL AND METHODS}

Study Design and Setting: Prospective pre-post comparative study was carried out at orthopaedic Out Patient Department (OPD), SFH-M, KSA. The study duration was around six months (September 2015 - March 2016).

Ethics and Research Approval: The review board of Security Forces Hospital, Makkah, has approved this study $(14 / 5 / 2015)$. Written informed consent form was read, explained and signed by all patients enrolled in the study.

Population and sampling: The study population was 109 patients, enrolled by random sampling. These patients then were assigned randomly to the treatment groups: celecoxib or ibuprofen. Patients were either considered or not in this study based on the following criteria:

Inclusion Criteria: Orthopaedic male/female out-patients who are 20 years of age or over; acute low back pain with duration of less than 6 weeks and patients who are prescribed Celecoxib $400 \mathrm{mg}$, and Ibuprofen $100 \mathrm{mg}$; only.

Exclusion Criteria: Patients with back pain due to malignancy, infection, metabolic disease; patients with back pain referred from other organs; pregnancy or lactating females; patients not complying because of mental disease or drug addiction and patients allergic to Celecoxib or Ibuprofen.

Evaluation: Two forms were employed in this study: Form 1 for demographic data of patients (Annex 1). Form 2 for numeric pain rating. The analgesic strengths used in this study was Celecoxib $400 \mathrm{mg}$, and Ibuprofen $100 \mathrm{mg}$. The decrease in pain score was calculated using a standardized system and was recorded on Day 5 and Day 10 of the patients follow up visits at orthopaedic OPD. The adverse drug reactions was recorded based on patient description. Pain was assessed using the modified World Health Organization pain scale (Annex 2).[12] The rating scale was adapted for Acute Low Back Pain ranged from 0 to 10: $0=$ No pain, $1-2=$ Mild pain, 3-5 = Moderate pain, 6-7 = Severe pain, $8-9=$ Very severe and $10=$ Untolerable pain.

Statistical Analysis: Statistical analyses and comparisons were performed by SPSS version 24 (IBM Corp. Released 2016. IBM SPSS Statistics for Windows, Version 24.0. Armonk, NY: IBM Corp.). Descriptive statistics i.e. frequency (percentage), mean (sd) and median (IQR) were used to describe the data, while paired sample t-test, Mann-Whitney test and Chi-Square test were used for the inferential statistics at alpha level 0.05.

\section{RESULTS}

One hundred and nine patients with acute low back pain who had presented to orthopaedic OPD of Security Forces Hospital-Makkah were recruited for this study. Among them 51 were prescribed Celecoxib ( $400 \mathrm{mg}$ ), while 58 were prescribed Ibuprofen $(100 \mathrm{mg})$. All the study population were Saudi nationals. Age range for Celecoxib group was $20-59$ years $(34.2 \pm 10.9)$, while for Ibuprofen group the age range was $22-57$ years $(31.3 \pm 7.3)$. Gender for both groups showed male preponderance of 69 versus 40 for females, giving a ratio close to 2:1 (Table 1). There were no significant differences between gender in terms of age in both study groups (Celecoxib, $\mathrm{p}=0.380$ and Ibuprofen, 


\section{ANNEX 1: Patient Data Collection: Questionnaire}

Serial Number Patient File Number

Age Gender ( A) Male

(B) Female

Occupation

Nationality ( A ) Saudi (B ) Non-Saudi

1. Pain Duration (A) Less than 6 weeks

(B) More than 6 weeks

2. Allergy to Celecoxib or Ibuprofen (A) Yes

(B) No

3. Analgesic prescribed now (A) Celecoxib

(B) Ibuprofen

4. Dose details

5. Side Effects

(A) Nausea

(B) Vomiting

(C) Headache

(D) Abdominal Pain

(E) Rash

( F ) Others (specify)

6. Smoker (A) Yes (No)

7. Exercise / Physical activity (A) Yes (B) No

8. If Yes, ( A ) Everyday (B) Once/Week (C) Twice/Week

9. Sick Leave given (A) Yes (B ) No

Table 1: Demographic features of orthopaedic patients who received Celecoxib or Ibuprofen for acute low back pain

\begin{tabular}{llll}
\hline & Celecoxib $(\mathbf{n}=51)$ & Ibuprofen $(\mathbf{n}=58)$ & $p$ value \\
\hline & $\mathbf{n}(\%)$ & $\mathbf{n}(\%)$ & $0.910^{*}$ \\
Mender & $32(62.7)$ & $37(63.8)$ & \\
Females & $19(37.3)$ & $21(36.2)$ & \\
Age (Median (IQR), years) & $30.0(25.0-46.0)$ & $30.0(25.0-37.0)$ & $0.408^{* *}$ \\
\hline
\end{tabular}

Note: * analysis was carried out using Chi-Square test; ** analysis was carried out using Mann-Whitney test 


\section{ANNEX 2: Rating Scale for Acute Low Back Pain}

Key : 0 = No pain, 1-2 = Mild pain, 3-5 = Moderate pain,

6-7 $=$ Severe pain, $8-9=$ Very severe, $10=$ Untolerable pain

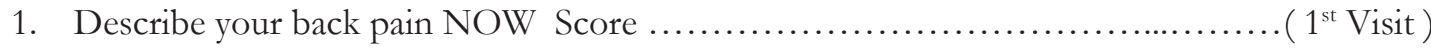

2. Describe your back pain AFTER DRUG INTAKE Score $\ldots \ldots \ldots \ldots \ldots \ldots \ldots \ldots\left(2^{\text {nd }}\right.$ Visit $)$

3. Do you have pain during walking NOW Score $\ldots \ldots \ldots \ldots \ldots \ldots \ldots \ldots \ldots \ldots \ldots\left(1^{\text {st }}\right.$ Visit $)$

4. Do you have pain during walking AFTER DRUG INTAKE Score $\ldots \ldots \ldots \ldots \ldots\left(2^{\text {nd }}\right.$ Visit $)$

5. Do you have pain when twisting NOW Score ........................... ( $1^{\text {st }}$ Visit $)$

6. Do you have pain when twisting AFTER DRUG INTAKE Score $\ldots \ldots \ldots \ldots \ldots . .\left(2^{\text {nd }}\right.$ Visit $)$

7. Do you have pain when sitting in chair NOW Score $\ldots \ldots \ldots \ldots \ldots \ldots \ldots \ldots \ldots$ ( ${ }^{\text {st }}$ Visit $)$

8. Do you have pain when sitting in chair AFTER DRUG INTAKE Score ........ ( $2^{\text {nd }}$ Visit $)$

9. Do you have pain when lying in bed NOW Score $\ldots \ldots \ldots \ldots \ldots \ldots \ldots \ldots \ldots \ldots$ ( $1^{\text {st }}$ Visit $)$

10. Do you have pain when lying in bed AFTER DRUG INTAKE Score ........... ( $2^{\text {nd }}$ Visit $)$

$\mathrm{p}=0.061)$.

The results of the test statistics (Figures 1 - 6) show significant reduction in pain by both Celecoxib and Ibuprofen at the second follow-up visit, for all patients during walking, twisting, and while sitting in chair. These pain reductions were analyzed by paired t-test and showed statistically significant $(p<0.05)$.

Celecoxib (400 mg) was superior to Ibuprofen (100 mg) in reducing acute low back pain of the orthopaedic study population (Figures $7-9$ ). The difference in pain reduction between the two drugs using paired t-test was statistically significant $(p<0.05)$.

Table 2 shows significant differences in pain score after the second visit for both celecoxib and ibuprofen groups. The pain scores of patients receiving celecoxib and ibuprofen were significantly improved from Day 5 to Day 10.

\section{DISCUSSION}

According to Atlas et al. and Griffin et al. low back pain is usually self-limited which many patients treat themselves and at times the pain can be severe. ${ }^{[13,14]}$ It could cause major pain, disability and costly medical condition.
There are several treatment options for patients with low back pain. There was statistical evidence of shortterm improvement and effectiveness of NSAIDs versus placebo. ${ }^{[14]}$ NSAID therapy was better than acetaminophen therapy but was not more effective than muscle relaxants or narcotics. ${ }^{[14]}$ All NSAIDs are equally effective with minimal side-effects. Our study compared the benefits of Celecoxib, a COX-2 selective inhibitor and Ibuprofen, a NSAID with reference to factors affecting acute low back pain among patients. The findings showed both drugs were effective in reducing pain when compared between the first and second visits. Further analysis comparing the two study groups indicated that celecoxib was more effective when compared to ibuprofen. This finding is contrast from a study by Salo et a ${ }^{[15]}$ No significant difference was found in their study when compared between celecoxib and ibuprofen among patients with acute pain in the emergency department. Van Tulder et al. noted that Ibuprofen is highly recommended than other NSAIDs because of its lower cost and GIT side-effects. In addition, according to them, the COX-2 inhibitors such as celecoxib or rofecoxib are more expensive and show no greater effectiveness than ibuprofen. One advantage of using the COX-2 is in patients who are significantly higher risk for GIT bleeding or peptic ulcer disease.

Back pain even though is usually acute is both a major 


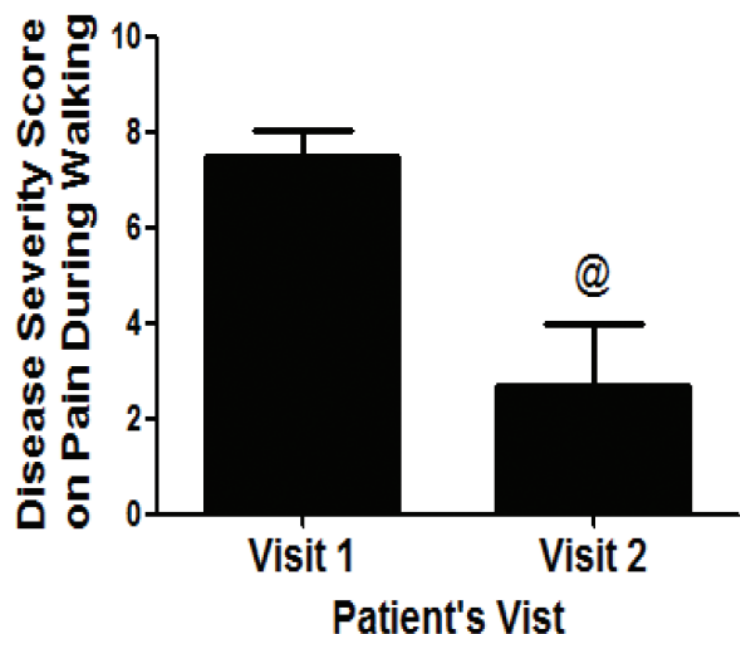

Figure 1: Celecoxib effect during walking

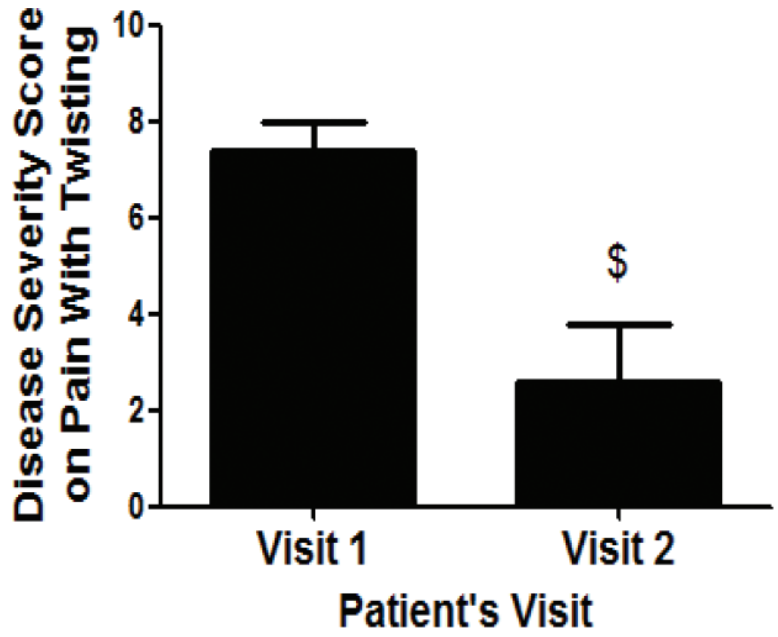

Figure 2: Celecoxib effect during twisting

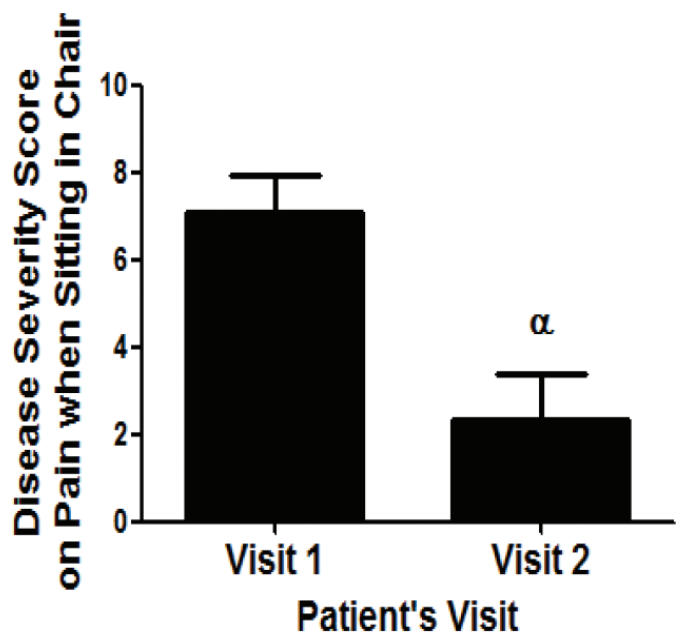

Figure 3: Celecoxib effect while sitting in chair

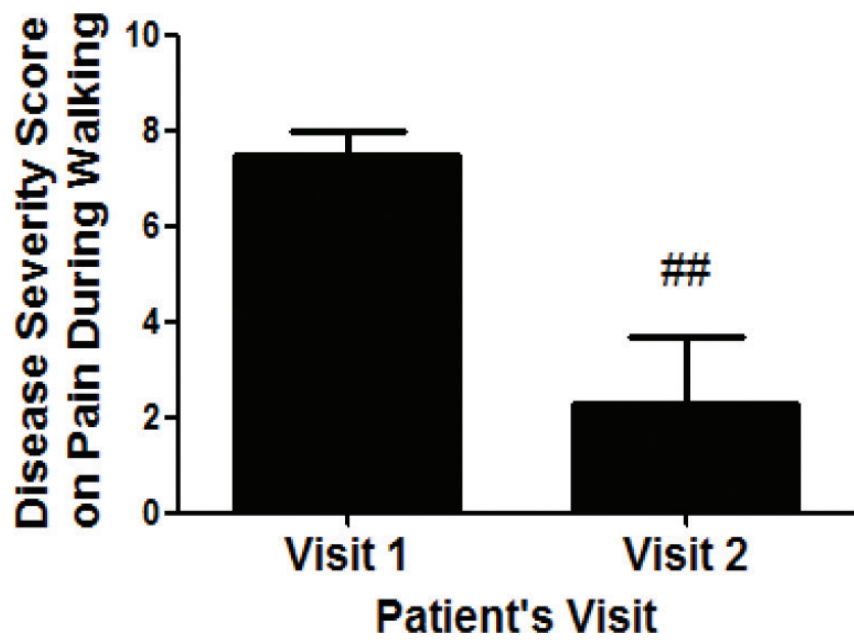

Figure 4: Ibuprofen effect during walking
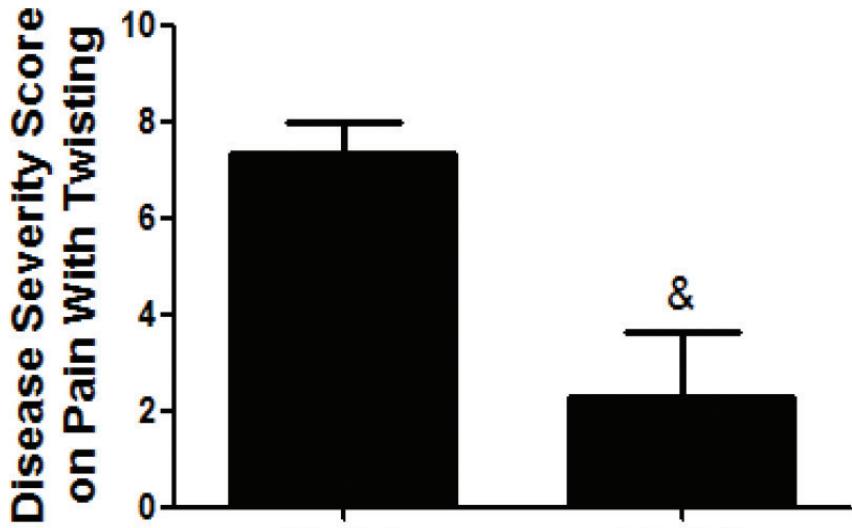

Visit 1

Visit 2

Patient's Visit

Figure 5: Ibuprofen effect during twisting

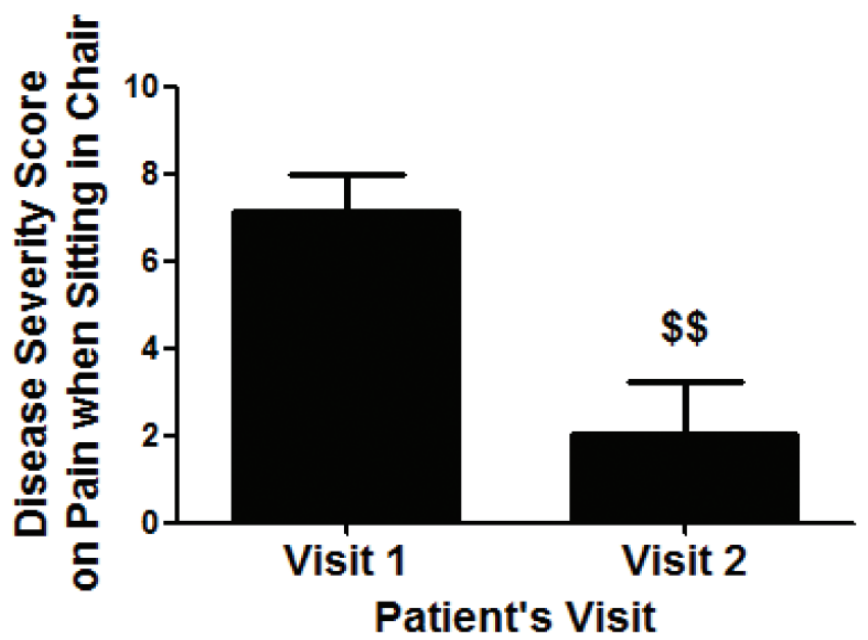

Figure 6: Ibuprofen effect while sitting in chair 


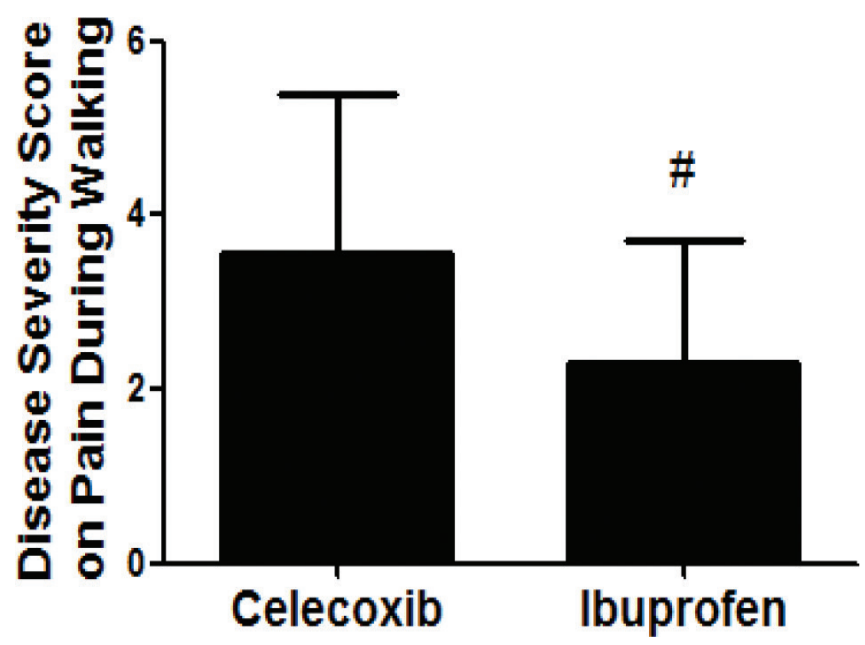

Figure 7: Celecoxib effect versus Ibuprofen effect during walking

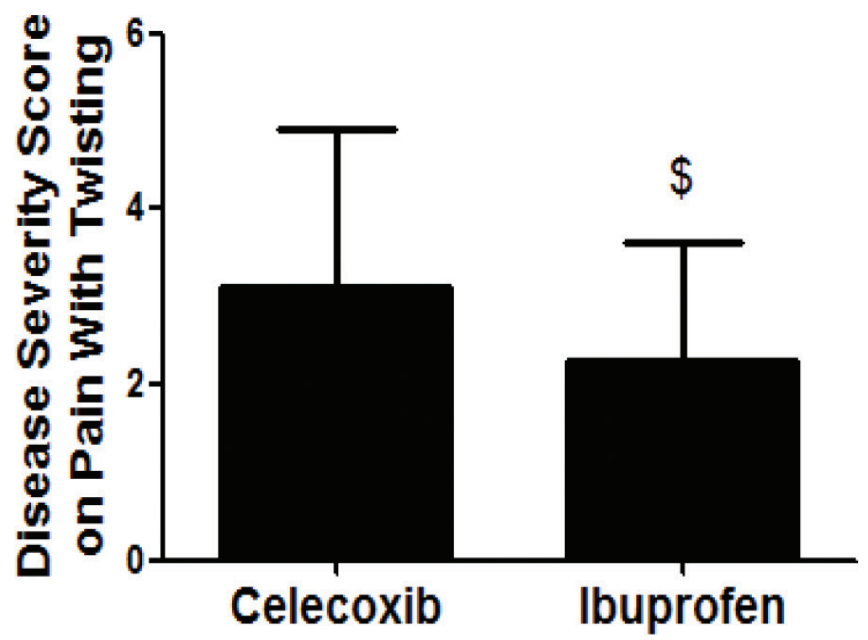

Figure 8: Celecoxib effect versus Ibuprofen effect during twisting

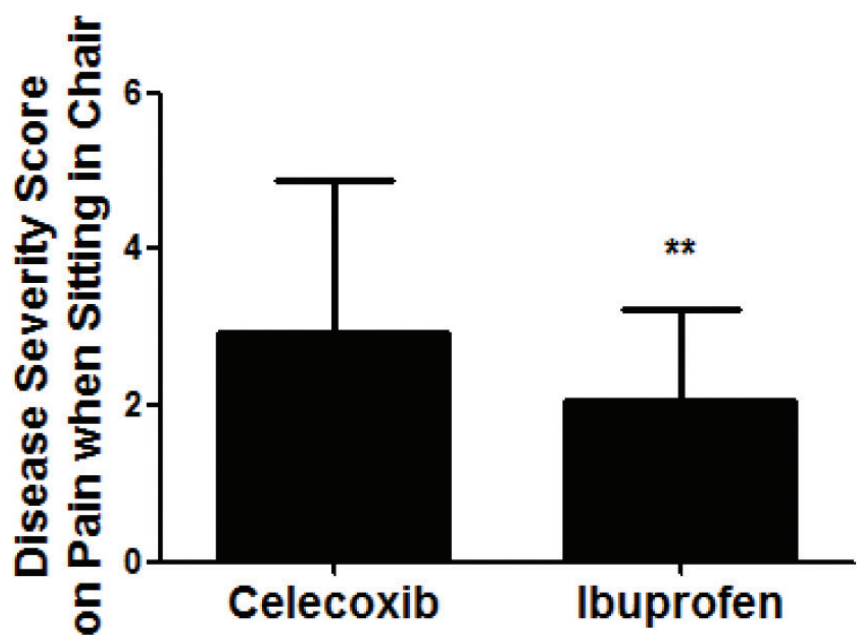

Figure 9: Celecoxib effect versus Ibuprofen effect while sitting in chair

cause of temporary disability and a challenge to medical and surgical treatment decisions. Patients must be taught on how to cope and getting the most cost-effective treatment. Our study did not take into consideration the cost of the treatment. Future study should look into drug side-effects and economic aspect of managing acute low back pain among the patients in the middle-east region. Drug therapy only provide temporarily relief for acute low back pain. Other modalities should also be explored. Non-steroidal anti-inflammatory drugs bring the pain to a tolerable level, but they should not be taken for short duration e.g. up to 12 days. $^{[12]}$

Our study has provided evidence on the use of NSAIDs among Arab patients in KSA. We had modified the WHO analgesic ladder to ensure its appropriateness in evaluating

\begin{tabular}{|c|c|c|c|}
\hline Item & Mean difference (SD) & t value & p value \\
\hline \multicolumn{4}{|l|}{ Celecoxib } \\
\hline Back pain (pre) - Back pain (post) & $4.765(1.124)$ & 30.271 & .000 \\
\hline Walk (pre) - Walk (post) & $4.824(1.276)$ & 26.996 & .000 \\
\hline Twist (pre) - Twist (post) & $4.784(1.172)$ & 29.164 & .000 \\
\hline Sit (pre) - Sit (post) & $4.765(1.106)$ & 30.762 & .000 \\
\hline Bed (pre) - Bed (post) & $5.314(1.421)$ & 26.702 & .000 \\
\hline \multicolumn{4}{|l|}{ Ibuprofen } \\
\hline Back pain (pre) - Back pain (post) & $5.155(1.182)$ & 33.222 & .000 \\
\hline Walk (pre) - Walk (post) & $5.172(1.365)$ & 28.849 & .000 \\
\hline Twist (pre) - Twist (post) & $5.069(1.282)$ & 30.105 & .000 \\
\hline Sit (pre) - Sit (post) & $5.103(1.252)$ & 31.038 & .000 \\
\hline Bed (pre) - Bed (post) & $5.552(1.379)$ & 30.667 & .000 \\
\hline
\end{tabular}

Note: * analysis was carried out using paired t-test 
acute low back pain. These modifications are necessary for knowledge transfer in pain management.

\section{CONCLUSION}

This study showed that both ibuprofen and celecoxib were effective in reducing pain when compared between the first and second visits. In addition, celecoxib was more effective when compared to ibuprofen.

Acknowledgements: Authors would like to thank all patients who have participated in this research.

\section{Source of support: None}

Conflict of interest: No conflict or competing interests.

\section{Abbreviations: None}

\section{REFERENCES}

1. Tulder M, Becker A, Bekkering $\mathrm{T}$, et al. Chapter 3 European guidelines for the management of acute nonspecific low back pain in primary care. Euro Spine J. 2006;15(2):S169-91.

2. Chou R, Huffman LH. Medications for acute and chronic low back pain: a review of the evidence for an American Pain Society/American College of Physicians Clinical Practice Guideline. Ann Intern Med. 2007;147(7):505-14.

3. Luo X, Pietrobon R, Curtis LH, Hey LA. Prescription of non-steroidal antiinflammatory drugs and muscle relaxants for back pain in the United States. Spine. 2004;29(23):E531-7.

4. Ayad AE, Ghaly N, Ragab R, Majeed S, Nassar H, Al Jalabi A, et al. Expert panel consensus on recommendations for pharmacological treatment of acute pain in the Middle East region. J Intl Med Research. 2011;39(4):1123-41.

5. Bhattarai S, Chhetri HP, Alam K, Thapa P. A study on the factors affecting low back pain and safety and efficacy of non-steroidal anti-inflammatory drugs in a tertiary care hospital at western Nepal. J Clinical Diagnostic Research. 2013;7(12):2752-8.

6. Al-Arfaj AS, Al-Saleh SS, Alballa SR, Al-Dalaan AN, Bahabri SA, AISekeit MA, et al. How common is back pain in Qassim region? Saudi Med J. 2003;24(2):170-3.

7. Moath-Binh H, Doaa-Abdelmoety, Waleed-Alshareef, Amer-Alghamdi, Fareed-Alhozali, Naif-Alfahmi, et al. Prevalence and risk factors of low back pain among operation room staff at a Tertiary Care Center, Makkah, Saudi Arabia: a cross-sectional study. Ann occupational Environ Med. 2016;28(1):11-7.

8. Attar SM. Frequency and risk factors of musculoskeletal pain in nurses at a tertiary care center in Jeddah, Saudi Arabia: A cross-sectional study. Bio Med Central Res Notes. 2014;7(1):61.

9. Keriri H. Prevalence and risk factors of low back pain among nurses in operating rooms, Taif, Saudi Arabia. Am J Res Commun. 2013;1(11):25-9

10. Abalkhail BA, Bahnassy AA, Ghabrah TM. Low back pain among Saudi workers in Jeddah. Saudi Med J. 1998;19(4):491-5.

11. Alghadir A, Zafar H, lqbal ZA. Work-related musculoskeletal disorders among dental professionals in Saudi Arabia. J Physio Therapy Sci. 2015;27(4):1107-12.

12. Ehrlich GE. Low back pain. Bulletin of the World Health Organization. 2003;81:671-6.

13. Atlas SJ, Deyo RA. Evaluating and Managing Acute Low Back Pain in the Primary Care Setting. J Gen Inter Med. 2001;16(2):120-31.

14. Griffin G, Tudiver F, Grant WD. Do NSAIDs help in acute or chronic low back pain? Am Fam Physician. 2002;65(7):1319-21.

15. Salo DF, Lavery D, Varma V, Goldberg J, Shapiro T, Kenwood A. A randomized clinical trial comparing oral celecoxib $200 \mathrm{mg}$, celecoxib 400 mg, and ibuprofen 600 mg for acute pain. Acad emic Med. 2003;10(1):22-30.

16. Tulder MW, Scholten RJ, Koes BW, Deyo RA. Non-steroidal antiinflammatory drugs for low back pain (Cochrane Review). In: The Cochrane Library. 2000;4. Oxford: Update Software.

Cite this article as: Alzahrani KH, Imam EA, Ibrahim MIM. A Pre-Post Study on Efficacy of Celecoxib and Ibuprofen for Acute Low Back Pain among Orthopaedic Patients at Security Forces Hospital, Makkah, Saudi Arabia. J Pharm Pract Community Med. 2017;3(4):200-6. 